\title{
Correction to: Modeling microbial ethanol production by S. aureus, $K$. pneumoniae, and $E$. faecalis under aerobic/anaerobic conditions - applicability to laboratory cultures and real postmortem cases
}

\author{
Glykeria Velivasi ${ }^{1} \cdot$ Nikolaos Kourkoumelis $^{2} \cdot$ Hercules Sakkas $^{3} \cdot$ Vassiliki A. Boumba $^{1,4}$
}

Published online: 28 August 2021

๑) Springer-Verlag GmbH Germany, part of Springer Nature 2021

Correction to: International Journal of Legal Medicine (2021)

https://doi.org/10.1007/s00414-021-02638-4

Originally, the article has been published online with error in author name. Iraklis Sakkas should be corrected to Hercules Sakkas.

The original article has been corrected.

Publisher's note Springer Nature remains neutral with regard to jurisdictional claims in published maps and institutional affiliations.

The original article can be found online at https://doi.org/10.1007/ s00414-021-02638-4.

Vassiliki A. Boumba

vboumba@uoi.gr; vassiliki.boumba@gmail.com

1 Department of Forensic Medicine \& Toxicology, Ioannina, Greece

2 Department of Medical Physics, Ioannina, Greece

3 Department of Microbiology, Ioannina, Greece

4 Faculty of Medicine, School of Health Sciences, University of Ioannina, 45110 Ioannina, Greece 